\title{
Research on Green Fund Efficiency Evaluation
}

\author{
Zeqia Tang1, Min Chen² \\ ${ }^{1}$ School of Finance, Anhui University of Finance and Economics, Bengbu, China \\ ${ }^{2}$ School of Economics, Anhui University of Finance and Economics, Bengbu, China \\ Email: tangzeqia@163.com
}

How to cite this paper: Tang, Z. Q., \& Chen, M. (2020). Research on Green Fund Efficiency Evaluation. Open Journal of Business and Management, 8, 1674-1683. https://doi.org/10.4236/ojbm.2020.84106

Received: July 1, 2020

Accepted: July 24, 2020

Published: July 27, 2020

Copyright $\odot 2020$ by author(s) and Scientific Research Publishing Inc. This work is licensed under the Creative Commons Attribution International License (CC BY 4.0).

http://creativecommons.org/licenses/by/4.0/

\begin{abstract}
As an important part of the green financial system, green funds have been in a growing development trend in recent years. In this paper, the DEA model and factor analysis method are used to conduct an empirical analysis of the selected 65 green funds. The comparison of efficiency shows that the efficiency of China's green funds has been in a high-efficiency area in recent years, but only some of the funds have reached the optimal state of DEA, and the multi-selected funds are specifically analyzed according to the comprehensive score ranking. Existing markets and institutions also need to uphold the concept of green development and adjust fund size, to promote technological innovation, and better achieve scale effect.
\end{abstract}

\section{Keywords}

Green Fund, DEA Model, Factor Analysis

\section{Introduction}

In recent years, my country's economic development has been in a growth trend. The urbanization process has been accelerating. The growing economy has also promoted the improvement of people's living standards, but environmental problems have gradually become prominent. Therefore, it is necessary to uphold the concept of green development and accelerate the reform of the ecological civilization system. Since the State Council issued the "Overall Plan for the Reform of the Ecological Civilization System" in 2015, the government has taken measures to address the existing problems, and the reform and construction of the ecological civilization system has gradually tended to be systematic, holistic, and collaborative. In addition, the improvement of the green financial system is conducive to the overall reform. The guidance issued by the government also provides great policy support for the development and improvement of the 
green financial system.

Green finance focuses on green energy, energy conservation and emission reduction projects and carries out operations and risk management, which can effectively use resources, improve the environment, and accelerate the reform of the ecological system. Green funds are an important part of the green financial system and focus on green investment. Low-carbon, environmentally friendly enterprises, promoting energy conservation and emission reduction, environmental protection and other work, help to improve social benefits. In recent years, under the favorable macro-policy and industry environment, green funds have been growing, and the development speed has gradually increased.

Based on the empirical data, this paper makes a reasonable evaluation of the efficiency of green funds based on the DEA model and factor analysis method to provide investment reference for relevant decision makers. In addition, this article selects efficiency evaluation indicators from different angles when conducting empirical analysis, analyzes how to improve fund efficiency for different indicators, concretely abstracts issues, and puts forward suggestions to further promote the healthy development of the industry.

\section{Literature Review}

The evaluation of fund efficiency has a relatively mature research system at home and abroad. Foreign scholars have explored the fund's returns and risks on the basis of asset portfolio theory and asset pricing models, and have proposed the Treynor Index, Sharp Index and Jensen Index as performance Evaluation indicators. Domestic scholars have also carried out certain empirical research based on efficiency evaluation.

Xie Huili et al. (2016) build a "Fama-French" three-factor model, evaluatesthe performance of environmental theme funds, and conduct continuous exploration in conjunction with the idea of "group iteration". The three-factor model has a high degree of fit, and the performance can be known based on the model. Generally, it is not sustainable. Li Xuefeng et al. (2019) explored the efficiency and sustainability of the fund by selecting the efficiency evaluation index and constructing a DEA model. He believes that although China's green funds have achieved relatively good development, they have certain advantages, but there is still room for improvement. Hao Jianping (2008) uses factor analysis to evaluate the performance of selected funds that meet the requirements. The results show that the development period of my country's equity funds is shorter, and the performance evaluation of different funds varies greatly. Jie Lei (2009) also evaluated the performance of ten open-end stock funds and gave investment opinions based on the factor analysis method. In addition, the results showed that there was a positive correlation between fund returns and risks. Yang Xin (2020) combined the PPP model to analyze the development process of green funds, and proposed existing problems and solutions from a new perspective. In this paper, combined with existing literature, this paper chose to construct a DEA 
model to evaluate the efficiency of the existing green fund market. Better achieve scale benefits, and more similarly analyze different funds through factor analysis to supplement green efficiency evaluation from the perspective of risk and return.

\section{Research Design}

\subsection{DEA Model}

This article selects the DEA model, uses linear programming and convex analysis to calculate and compare the relative efficiency between decision-making units, and evaluates the efficiency on the basis of the concept of relative efficiency. The CCR model is an input-oriented model in the DEA model, and the efficiency measurement is calculated through the envelope analysis of the data, which has a strong practical application (Wang \& Dong, 2020).

Assuming that the scale benefit remains unchanged, a CCR-input-oriented model is established. Assuming that there are $\mathrm{N}$ types of green funds, each type of green fund has $\mathrm{n}$ types of input and $\mathrm{m}$ types of output, and the efficiency of green funds should satisfy the following formula. In the $\mathrm{N}$ formula, $X_{j}$ and $Y_{j}$ are the n-dimensional input vector and output vector of the J decision unit, respectively. Where $\theta$ satisfies $0 \leq \theta \leq 1$, if $\theta<1$, the decision unit is in an invalid state, and if $\theta=1$, the decision unit is in an effective state. $\delta_{j}$ is a linear combination of input and output indicators.

$$
\begin{gathered}
\sum_{j=1}^{N} X_{j} \delta_{j} \leq \theta X_{k} \\
\sum_{j=1}^{N} Y_{j} \delta_{j} \geq Y_{k} \\
\delta_{j} \geq 0, j=1,2, \cdots, N
\end{gathered}
$$

\subsection{Factor Analysis}

Selecting the impact indicators, in order to reduce the loss of information, the same essential variables are grouped into a factor, and the representative factors are extracted through dimensionality reduction to reduce the number of variables in the model and simplify data research (Du \& Zheng, 2020).

Suppose there are n samples, where $X$ is an observable random variable, the linear function expression between the selected factors $F$ and $X$ is:

$$
X_{i}=\sum_{j=1}^{m} \alpha_{i j} F_{j}+\varepsilon_{i}
$$

$\varepsilon$ is a special factor, which is usually ignored in practice and can also be expressed by constructing a mathematical model, The mathematical model is:

$$
F_{i}=b_{i 1} X_{1}+b_{i 2} X_{2}+b_{i 3} X_{3}+\ldots+b_{i n} X_{n}
$$

$(n=1,2, \ldots)$, and $F_{i}$ is the score of the $i$-th factor. 


\section{Empirical Analysis}

\subsection{Data Selection and Processing}

In this paper, iFinD software is used to select funds for environmental protection, new energy, beautiful China, etc. through the Flush Flush theme classification fund, and fund selection and export data. In order to study the accuracy of the results and the feasibility of calculation, remove the incomplete data in the selected indicators Funds, the final research sample fund is 65 , the exported data is the 2019 annual report of the fund, and the relevant ratio is 52 weeks before the latest cut-off date to the cut-off date. During this period, China's green funds have gradually matured, and the number and scale have increased significantly, Used to reflect the overall characteristics of green funds (An, 2018).

The selected input indicators are: fund risk measurement index: sharp index; fund cost: custody fee payable, management manager compensation payable (annual); (Shan, 2018) fund manager personal ability measurement index: stock selection ability index. And the output index is the direct measurement of the fund's income: cumulative unit net worth growth rate, average return rate. See Table 1.

In order to ensure that the input and output indicators are not related, we extract the principal components of the derived data, and each indicator is multi-attribute normalized. The calculation formula is:

$$
Z_{i j}=0.9 \times \frac{Z_{i j}-b_{i j}}{a_{i j}-b_{i j}}+0.1
$$

where $a_{i j}$ and $b_{i j}$ are the maximum and minimum values of the $j$ th index, respectively.

\subsection{Efficiency Analysis of Green Funds}

1) DEA model

The processed input and output indicator data are respectively entered into Deap2.1 software according to the month, and the technical efficiency (comprehensive efficiency), pure technical efficiency and scale efficiency value and scale return of the 65 green funds in the sample period are obtained. Due to the large number of choices, the data is grouped during the analysis. The efficiency value is initially grouped as 1 , and each decrease of 0.1 is reduced to one group. The scale returns are divided into 3 groups. In addition, the model is also used to estimate that the DMU is in increasing and decreasing returns to scale. The number of green funds in the unchanging stage is 54,1 and 10 respectively. The distribution of specific software calculation results is shown in Table 2.

In the DEA model, the efficiency of the green fund increases with the increase of the efficiency value. The lower the efficiency value, the less equitable the input-output ratio of the fund is. There are relatively too many inputs, but poor output. Assume that 0.5 is the efficiency boundary, greater than 0.5 is the high efficiency area, and less than 0.5 is the low efficiency area. It can be seen from 
Table 1. Evaluation index system of green fund efficiency.

\begin{tabular}{cc}
\hline First-level indicators & Secondary indicators \\
\hline Input indicators & sharp index \\
& Custody fees payable \\
& Payable to management managers \\
Output indicators & Stock picking ability \\
& Cumulative unit net worth growth rate \\
& Average yield \\
\hline
\end{tabular}

Table 2. Number of funds in different efficiency ranges.

\begin{tabular}{cccc}
\hline Project & Technical efficiency & Pure technical efficiency & Scale efficiency \\
\hline 1 & 10 & 19 & 10 \\
$0.9-1$ & 7 & 27 & 16 \\
$0.8-0.9$ & 12 & 14 & 11 \\
$0.7-0.8$ & 10 & 4 & 11 \\
$0.6-0.7$ & 10 & 0 & 8 \\
$0.5-0.6$ & 8 & 0 & 4 \\
$0.4-0.5$ & 7 & 1 & 5 \\
$0.3-0.4$ & 1 & 0 & 0 \\
Mean & 0.7528 & 0.9277 & 0.8092 \\
\hline
\end{tabular}

the calculation results that the technical efficiency of green funds, pure technical efficiency and scale efficiency are mostly greater than 0.5 , and the funds in the stage of increasing returns to scale are as high as $83.08 \%$, indicating that most green funds are more efficient. In addition, comparing the averages of the three efficiencies shows that pure technology is more efficient, fund management and technology are more advanced, and it is better to maximize the output of the given input, but the scale efficiency is lower, and the existing fund input and output allocation is unreasonable. Adjust the scale of funds, improve the allocation of funds, further improve the overall efficiency, and achieve economies of scale (Shi et al., 2017).

There are also some differences in the efficiency values of different types of funds. Some funds have an efficiency value of 1 , which performs well, but there are also a small number of funds whose efficiency values are in low-efficiency areas. Certain planning adjustments are required to achieve optimal bagging. In addition, from the relationship of comprehensive efficiency, pure technical efficiency and scale efficiency, we can see that the fluctuation of comprehensive efficiency is closely related to the fluctuation of pure technical efficiency and scale efficiency. For specific funds, the size relationship between the three and the low value of a certain efficiency value can be used to determine the shortage, specifi- 
cally adjust the technical capabilities and asset allocation, and take measures to optimize to achieve the DEA effective state (Qin \& Wang, 2019).

2) Factor analysis

When performing factor analysis, it is necessary to conduct a feasibility test on the data and pass the test, so that the results of the factor analysis have credibility. The results of data feasibility test are obtained through SPSS analysis, as shown in the table. According to the test results, the $\mathrm{KMO}$ value is $0.544>0.5$. The $P$ value of the Buckley sphere test is 0.000 , rejecting the null hypothesis, and the selected index is suitable for factor analysis. See Table 3.

The common factor variance can reflect the information extracted from each original variable (Zeng et al., 2020). According to the table, most indicators in the index system have been extracted about $90 \%$ of the information, indicating that most of the original variable information has been saved. The model can reflect the basic situation of green fund efficiency. See Table 4.

The common factor is extracted based on the variable eigenvalue greater than 1 , and the total variance contribution rate for each year is solved. The cumulative contribution rate of the rotation square and the loading factor were $98.1 \%$, $98.1 \%, 75.3 \%, 94.8 \%$, and $91.4 \%$, respectively, indicating that the cross-sectional data can better explain the fund efficiency evaluation system. Based on factor analysis, the component score coefficient after rotation and the comprehensive factor score of green fund efficiency under the factor analysis method can be obtained. The component score coefficients after rotation are shown in Table 5.

The public factors extracted by factor analysis conform to economic significance, and can be used for the purpose of factor analysis. In addition, from the table, component 1 has a better overall situation for the custody fee payable and the manager's remuneration payable, so this article refers to component 1 as the custody factor. Component 2 has a better overall situation in terms of cumulative unit net worth growth, average yield, and stock picking ability, so the component is named the yield factor. On this basis, the annual efficiency comprehensive score of the green fund is calculated, and the results are shown in Table 6.

From the ranking of scores, we can see that there is a large gap between different funds, and most funds with a negative overall score have a certain objective impact on the overall market efficiency. Among them, Wells Fargo China

Table 3. KMO and Bartlett inspection results.

\begin{tabular}{|c|c|c|}
\hline \multicolumn{3}{|c|}{ KMO and Bartlett inspection } \\
\hline \multicolumn{2}{|c|}{ KMO sampling suitability measure } & 0.544 \\
\hline \multirow{3}{*}{ Bartlett sphericity test } & Approximate chi-square & 400.723 \\
\hline & Degrees of freedom & 15 \\
\hline & Distinctiveness & 0 \\
\hline
\end{tabular}


Table 4. Common factor variance.

\begin{tabular}{ccc}
\hline Index & Initially & Extract \\
\hline Custody fees payable & 1.000 & 0.989 \\
Manager's remuneration payable & 1.000 & 0.995 \\
Cumulative unit net worth growth & 1.000 & 0.606 \\
Average yield & 1.000 & 0.923 \\
Stock picking ability & 1.000 & 0.846 \\
\hline
\end{tabular}

Table 5. Rotated component matrix.

\begin{tabular}{ccc}
\hline Index & \multicolumn{3}{c}{ ingredient } \\
\cline { 2 - 3 } & 1 & 2 \\
\hline Custody fees payable & - & 0.981 \\
Manager's remuneration payable & - & 0.981 \\
Cumulative unit net worth growth & 0.753 & - \\
Average yield & 0.948 & - \\
Stock picking ability & 0.914 & - \\
\hline
\end{tabular}

Table 6. Comprehensive score table.

\begin{tabular}{|c|c|c|c|c|c|c|c|}
\hline Fund code & $\begin{array}{l}\text { Factor } 1 \\
\text { score }\end{array}$ & $\begin{array}{l}\text { Factor } 2 \\
\text { score }\end{array}$ & $\begin{array}{c}\text { Comprehensive } \\
\text { Score }\end{array}$ & Rank & Fund code & $\begin{array}{l}\text { Factor } 1 \\
\text { score }\end{array}$ & $\begin{array}{c}\text { Factor } 2 \\
\text { score }\end{array}$ \\
\hline 150212 & 2.5948 & 2.3828 & 2.4975 & 1 & 5928 & 0.4339 & -0.7197 \\
\hline 1410 & 1.9860 & 2.5641 & 2.2512 & 2 & 598 & 0.0466 & -0.3321 \\
\hline 161028 & 0.4689 & 2.8547 & 1.5633 & 3 & 150280 & 0.3796 & -0.7441 \\
\hline 1975 & 0.7070 & 1.9772 & 1.2896 & 4 & 150185 & -0.0582 & -0.2791 \\
\hline 663 & 1.2437 & 0.3821 & 0.8485 & 5 & 1208 & -0.7042 & 0.4676 \\
\hline 977 & 1.7556 & -0.3503 & 0.7896 & 6 & 822 & 0.2680 & -0.6816 \\
\hline 540008 & 1.7238 & -0.4723 & 0.7164 & 7 & 150238 & 0.1416 & -0.6163 \\
\hline 696 & -0.4026 & 1.8060 & 0.6105 & 8 & 5571 & 0.0914 & -0.6279 \\
\hline 1158 & -0.7948 & 2.2360 & 0.5954 & 9 & 5572 & 0.0715 & -0.6247 \\
\hline 1471 & 0.8794 & 0.1728 & 0.5553 & 10 & 512580 & -1.0397 & 0.5022 \\
\hline 1166 & -1.0680 & 2.4112 & 0.5279 & 11 & 4925 & -0.3784 & -0.3535 \\
\hline 409 & 1.3742 & -0.4845 & 0.5216 & 12 & 164905 & -0.5465 & -0.2745 \\
\hline 150211 & -1.9690 & 3.3221 & 0.4580 & 13 & 5037 & -0.3237 & -0.5772 \\
\hline 1245 & 0.1623 & 0.7996 & 0.4546 & 14 & 160640 & -0.3336 & -0.5843 \\
\hline 1156 & 1.0648 & -0.2753 & 0.4501 & 15 & 5038 & -0.3447 & -0.5737 \\
\hline 3834 & 0.6721 & 0.1679 & 0.4408 & 16 & 150324 & -0.3168 & -0.6079 \\
\hline 5668 & 1.1473 & -0.4747 & 0.4033 & 17 & 163114 & -0.7433 & -0.1641 \\
\hline 4640 & 1.1678 & -0.5706 & 0.3704 & 18 & 164821 & -0.4925 & -0.5673 \\
\hline
\end{tabular}




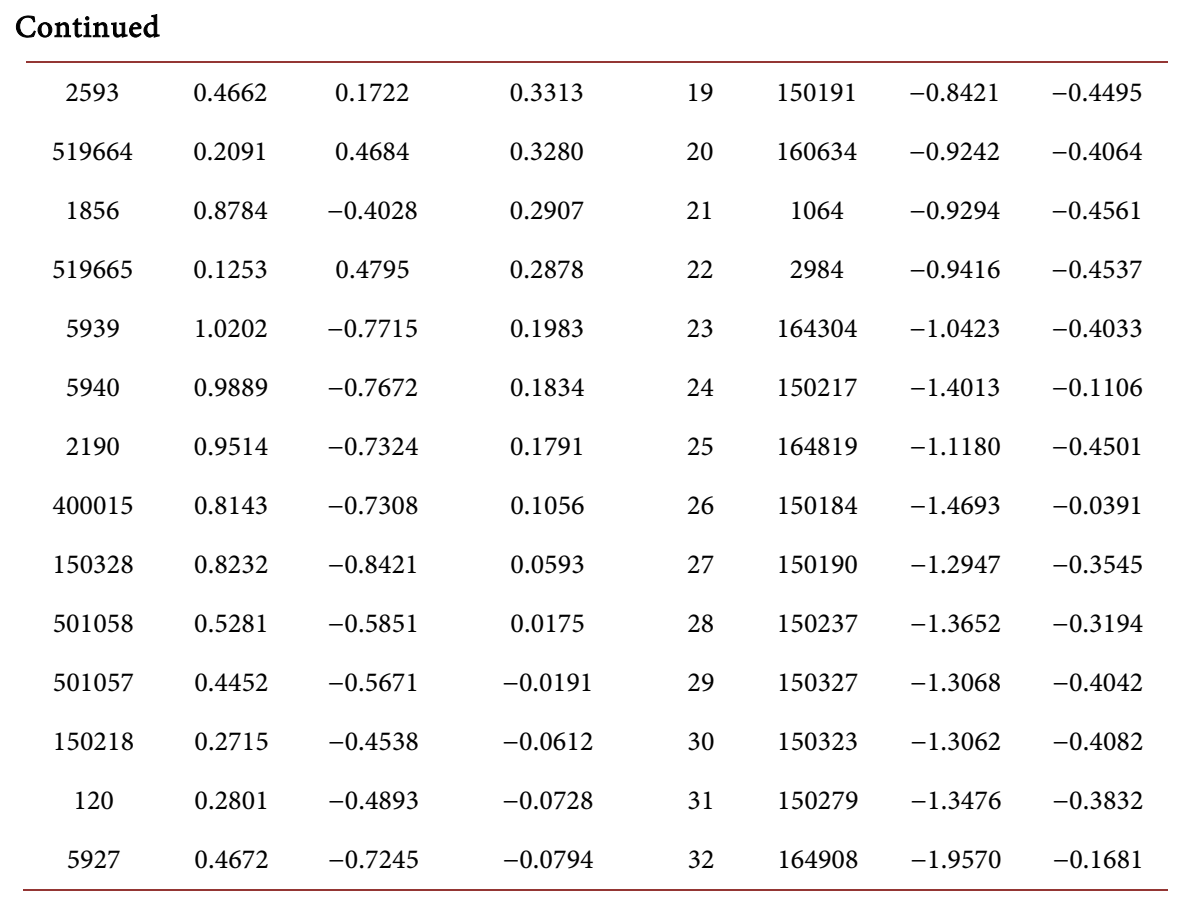

Securities New Energy Automobile B (150212), Cinda Australia Silver New Energy Industry (1410). Wells Fargo China Securities New Energy Automobile (161028) ranks in the top three in terms of overall score, with good performance and consistent with the analysis of the DEA model. The technical efficiency of the three green funds is 1, reaching the DEA optimal state and being in scale returns increasing stage. The three funds of Bank of Communications Schroder CSI Environmental Governance Index (164908), Penghua CSI New Energy A (150279), ICBC Credit Suisse CSI Environmental Protection Industry A (150323) have low comprehensive scores and unstable efficiency performance, compared with the DEA model. It can be seen that the technical efficiency of these three funds is less than 0.5 , which is in a low-efficiency area. Therefore, institutions need to conduct research on the existing market, improve product management and system construction, and continue to innovate in the fiercely competitive fund market to enhance their own strength. Achieve the healthy development of the fund and promote market construction.

\section{Main Conclusion and Policy Recommendation}

Every asset has a specific institution to rate it. An effective performance rating system is conducive to investment choices and market improvement. The particularity of green funds requires it to have a more complete system from fund creation to exit (Guan \& Zhao, 2020).

This article is based on the DEA input-oriented model and factor analysis method. According to empirical analysis, China's green fund market efficiency is in a good DEA state. After years of development, green funds have gradually matured and stable management teams. The risk management capabilities of 
fund managers are selected. The stock capacity has also been improved to a certain extent, which is conducive to investor trust. However, some of the green efficiency has not reached the optimal state, the overall score is negative, and the performance is poor. Therefore, the market also needs to carry out further planning and improvement to maintain green sustainable development. In addition, the research results also have a certain reference significance for specific funds. The synthesis of the relationship between the three efficiencies also implies that managers should pay attention to technology investment, or adjust the fund size in further development, and take targeted measures to achieve scale effects. According to the results of factor analysis, a better investment portfolio can be selected to reduce risks while increasing returns.

In terms of policies and systems, the central and local governments need to keep abreast of market development trends and give correct judgments. Through the formulation of policies and systems, they will broaden financing channels, adjust singular investment structures, and promote the implementation of various green finance pilot projects. The government should maintain the sustainable development of the fund market, improve the institutional framework of the green fund, speed up the establishment of articles of association, systems, etc., clarify the responsibilities and obligations of each responsible entity, improve the incentive mechanism of green funds, and implement the progress of green fund projects. In addition, the reform and innovation of green funds, product upgrades, and structural expansion should be actively promoted. In addition to institutional policy support, the government may consider establishing a central-level green industry investment fund or green economic development fund dedicated to promoting green economic development. Provide sustainable innovation to further drive innovation.

In terms of funds and talents, my country's development of green funds should be adapted to local conditions, actively introduce foreign investment, attract professional talents, and integrate with the international standards, so as to obtain financial and technical support from international financial institutions. In terms of resource optimization, the government can promote effective mergers and acquisitions of environmental protection funds, actively do publicity work, stimulate the social responsibility of major enterprises, and then fully attract private capital, participate in the construction of environmental protection, and promote the green fund Marketization, thereby promoting the transformation of China's green economy.

\section{Conflicts of Interest}

The authors declare no conflicts of interest regarding the publication of this paper.

\section{References}

An, G. J. (2018). Development Trend of China Green Fund. China Finance, No. 19, 
81-82.

Du, L., \& Zheng, L. C. (2020). Research on the Quality Evaluation of Green Finance Policy in China. Journal of Wuhan University (Philosophy and Social Sciences Edition), 73, 115-129.

Guan, L. J., \& Zhao, W. (2020). DEA-Malmquist-Based Rural Infrastructure Supply Efficiency Evaluation. Statistics and Decision, 36, 172-175.

Hao, J. P. (2008). Stock Fund Performance Evaluation Based on Factor Analysis Method. Finance and Accounting Monthly, No. 17, 38-40.

Jie, L. (2009). Comprehensive Evaluation of Fund Investment Efficiency Based on Factor Analysis Method. Contemporary Economy, No. 20, 84-86.

Li, X. F., Li, Y. J., \& Hu, X. Y. (2019). Research on Green Fund Efficiency and Sustainability. Property Right Guide, No. 11, 37-43.

Qin, Y. T., \& Wang, J. (2019). Research on the Status Quo and Problems of Green Finance Development in China. Tianjin Economics, No. 12, 20-25.

Shan, K. J. (2018). Analysis of the Operation of My Country's Green Development Fund. Financial Theory and Practice, No. 11, 93-96.

Shi, Y. P., Liu, B. J., \& Ma, Q. Q. (2017). Performance Analysis of My Country's Environmental Protection Fund-Comparing Other Socially Responsible Investment Funds and Traditional Mutual Funds. Contemporary Economic Management, 39, 93-97.

Wang, B., \& Dong, Z. N. (2020). The Perfect Path of My Country's Green Financial System-Taking Green Bonds, Green Credit and Green Funds as Examples. Finance and Economics, No. 4, 84-90.

Xie, H. L., Zhang, C. H., \& Jin, H. (2016). Performance and Sustainability Analysis of My Country's Environmental Protection Theme Fund-Based on Fama-French Three-Factor Model. Productivity Research, No. 4, 55-59.

Yang, X. (2020). Green Technology Promotes Beijing-Tianjin-Hebei Ecological Coordinated Development. Hebei Normal University, Shijiazhuang, 11-18.

Zeng, G. D., Huang, D. Y., Chen, H. Y., Huang, L. M., \& Feng, Y. D. (2020). Research on Liuzhou Agricultural Product Logistics Transportation Efficiency Based on Input-Oriented DEA Model. Chinese Market, No. 14, 26-27. 